\title{
In-house quality control material of nicarbazin and narasin in eggs: preparation and inter-laboratory evaluation
}

\author{
Małgorzata Olejnik • Piotr Jedziniak • \\ Teresa Szprengier-Juszkiewicz • Jan Żmudzki
}

Received: 18 December 2012/ Accepted: 28 June 2013/Published online: 14 July 2013

(C) The Author(s) 2013. This article is published with open access at Springerlink.com

\begin{abstract}
Coccidiostats are a group of pharmacologically active substances widely used in veterinary practice. Their residues are detected relatively often in poultry tissues and egg samples analyzed as part of official residue control programs in the European Union. Therefore, accuracy of quantitative results needs to be monitored through internal and external quality control studies. In addition, the use of materials containing incurred residues would be welcome to for ongoing monitoring of the method accuracy. Unfortunately, in the field of veterinary drug residues, certified reference materials are often unavailable. Therefore, in-house quality control material of incurred lyophilized eggs containing narasin and nicarbazin has been produced and characterized. The eggs originated from hens receiving feed with coccidiostat premix Maxiban were mixed to obtain presumed concentrations of residues and freeze-dried. Homogeneity of the material was verified by the duplicate analysis of ten random samples, and the results proved that the between samples variation was negligible in comparison with the method repeatability. No measurable loss of analytes was observed within 1 year; the slope of the regression line of the results of stability measurements was not significantly different from zero. The assigned values were expressed as medians of the results of inter-laboratory comparison performed in four different European laboratories; the uncertainty of the material was estimated, taken into consideration all above
\end{abstract}

M. Olejnik ( $₫)$ · P. Jedziniak · T. Szprengier-Juszkiewicz •

J. Żmudzki

Department of Pharmacology and Toxicology, National

Veterinary Research Institute, Al. Partyzantow 57,

24-100 Pulawy, Poland

e-mail: malgorzata.olejnik@ piwet.pulawy.pl tests, resulting in $(14.4 \pm 2.53) \mu \mathrm{g} / \mathrm{kg}$ for nicarbazin and $(7.91 \pm 1.52) \mu \mathrm{g} / \mathrm{kg}$ for narasin.

Keywords Reference material - Residues - Coccidiostat . Narasin $\cdot$ Nicarbazin

\section{Introduction}

Analytical methods used in official residue control [1] should be verified during validation and meet specific, detailed performance criteria described in European legislation [2]. The performance of methods in routine practice requires ongoing quality assurance checks through internal quality control and inter-laboratory studies, which may include proficiency studies. Because of the complexity of matrices and low target levels of analytes, ensuring reliability of obtained results requires a lot of effort [3].

In both initial (validation study) and successive verification of methods (quality control), the choice of proper test sample plays a significant role. It should resemble the one analyzed routinely as much as it is possible and in ideal situation; it should contain naturally incurred residues rather than artificial processed such as fortification. Some certified reference materials are available [4-7] but they do not and, for economical reasons, cannot [8] cover the whole scope of compounds and matrices analyzed in the residue control. Therefore, reference materials of wellcharacterized homogeneity and stability are often produced and used [9-11]. They are called in-house reference materials (HRMs), "laboratory reference materials" or "quality control materials" (QCMs) and are important part of the laboratory quality system. Although their use for calibration and (partly) validation is limited, they can be successfully applied in method development and quality 
control. For example, they can be used for the optimization of hydrolysis conditions for conjugated compounds and to compare the precision/accuracy of the analyses of incurred and spiked materials.

The determination of residues of coccidiostats in food of animal origin is an important issue for official control laboratories due to the relatively high percentage of positive samples, especially in eggs and poultry [12]. Among non-compliant results in European Union, nicarbazin appears most frequent, followed by the ionophore coccidiostats [12, 13]. As a result, a QCM of incurred lyophilized egg containing nicarbazin and narasin was considered the most crucial for practical and administrative reasons.

\section{Materials and methods}

Production of the incurred egg samples material

Eggs containing dinitrocarbanilide (DNC, nicarbazin marker residue) and narasin (NAR) residues were obtained during the experiment, which design has been described elsewhere [14]. In brief, a flock of 50 hens received Maxiban (feed containing NAR and NIC, $80 \mathrm{mg} / \mathrm{kg}$ each) for the consecutive 14 days. For the next 21 days and during equilibration period, the birds received narasincontaminated feed $(5.13 \mathrm{mg} / \mathrm{kg})$. Five eggs were collected daily; they were broken, mixed, and stored at $-20{ }^{\circ} \mathrm{C}$. Egg samples were analyzed with LC-MS/MS method described previously [15]. Based on the results of these analyses, eggs for the preparation of QCM were chosen in such a way to obtain ca $15 \mu \mathrm{g} / \mathrm{kg}$ DNC and $7.0 \mu \mathrm{g} / \mathrm{kg}$ NAR in the target raw material.

\section{Lyophilization and storage of egg samples}

Egg samples selected for the preparation of the QCM were thawed in a refrigerator $\left(2-10^{\circ} \mathrm{C}\right)$ for $16 \mathrm{~h}$. The samples were subsequently equilibrated to room temperature, mixed with negative control material (eggs not containing coccidiostats) to obtain ca $7 \mu \mathrm{g} / \mathrm{kg}$ NAR and $15 \mu \mathrm{g} / \mathrm{kg} \mathrm{DNC}$, and homogenized by ultra-turrax (30 min). Egg samples were then transferred to glass Petri dishes in the layers ca $5 \mathrm{~mm}$ thick and weighed. The samples were frozen and transferred to a freeze-dryer (Alpha 1-4 LSC, Martin Christ, Germany) for $48 \mathrm{~h}$ with shelf temperature $-18{ }^{\circ} \mathrm{C}$ and vacuum 1.03 mbar. Following lyophilization, Petri dishes were weighed again to calculate water loss. The obtained material was mixed in the blender, mixed in Turbula T2F shaker-mixer (Glen Mills, USA), and divided into $2.36 \mathrm{~g}$ subsamples (equivalent to $10 \mathrm{~g}$ of reconstituted sample) that were stored in polypropylene $50 \mathrm{~mL}$ tubes in the dark at the temperature below $-18{ }^{\circ} \mathrm{C}$.
Verification of the material in National Veterinary Research Institute (NVRI)

\section{Standards and reagents}

Dinitrocarbanilide (DNC), narasin (NAR), and nigericin (NIG) were obtained from Sigma (Germany), and DNC-d8 was purchased from Witega (Germany). Acetonitrile (ACN) and methanol, both LC-MS grade, and ammonium formate, HPLC grade, were purchased from JT Baker (Germany). Dimethylsulfoxide (DMSO) and formic acid were obtained from Sigma (Germany). SPE cartridges Oasis HLB (60 mg) were purchased from Waters (USA). Hexane puriss p.a. was obtained from POCh (Poland), centrifugal filters $0.2 \mu \mathrm{m}$, Nanosep MF from Pall (USA), and ultrapure water (resistance $>18 \mathrm{~m} \Omega$ ) was obtained from Milli-Q system (Millipore, France).

Stock standard solutions $(1000 \mu \mathrm{g} / \mathrm{mL})$ were prepared in DMSO (DNC, DNC-d8) or acetonitrile (NAR, NIG). The intermediate standard solutions (100 and $10 \mu \mathrm{g} / \mathrm{mL})$ were prepared in acetonitrile. The mixed standard solution $(0.25 \mu \mathrm{g} / \mathrm{mL})$ was used for the sample fortification. The mixed solution of internal standards (IS) in acetonitrile contained $2.5 \mu \mathrm{g} / \mathrm{mL} \mathrm{NIG}$ and $0.5 \mu \mathrm{g} / \mathrm{mL}$ DNC-d8. Stock, working, and mixed standard solutions were stable for 12 , 6 , and 2 months, respectively, when stored in $2-10{ }^{\circ} \mathrm{C}$.

\section{Determination of nicarbazin and narasin in eggs by $L C-M S / M S$}

NIC and NAR residues were measured in egg samples using a LC-MS/MS method, which has been described elsewhere [15]. In brief, the sub-sample (2.36 g) of lyophilized eggs was thawed and $7.64 \mathrm{~mL}$ of water was added. Samples were vortex-mixed, sonicated for $15 \mathrm{~min}$, and further vortexed for $1 \mathrm{~min}$. The rehydrated egg samples were weighed $(2 \mathrm{~g})$ into a polypropylene tube, fortified with $20 \mu \mathrm{L}$ of IS, and extracted with acetonitrile. Extracts were cleaned up on Oasis HLB SPE cartridges. The chromatography (Agilent 1100) was performed on Luna PhenylHexyl $3 \mu \mathrm{m}$, $2.0 \times 150 \mathrm{~mm}$ column (Phenomenex) with the gradient elution program (acetonitrile, methanol, and $0.01 \mathrm{~mol} / \mathrm{L}$ ammonium formate buffer, $\mathrm{pH}$ 4.0) [15]. The mass spectrometer (API 3000, AB Sciex, Canada) equipped with electrospray ionization source was operated in selected reaction monitoring (SRM) mode and every sample was injected twice. In the first injection (positive ionization), NAR $(\mathrm{m} / z, 787.6$ to $\mathrm{m} / z, 531.4$ and 431.0$)$ and NIG $(\mathrm{m} / z, 747.5$ to $m / z$ 703.5) transitions were monitored. DNC and DNC-d8 were analyzed in negative mode. The monitored transitions were $\mathrm{m} / \mathrm{z} 301.0$ to $\mathrm{m} / \mathrm{z} 137.0$ and 107.0 for DNC and $\mathrm{m} / \mathrm{z} 309.0$ to $\mathrm{m} / \mathrm{z}, 141.0$ for DNC-d8. The method was validated according to Commission Decision 2002/657/EC [2, 15]. 


\section{Homogeneity study}

Homogeneity study was performed according to the procedure described in IUPAC Technical Report [16]. Ten randomly selected samples were analyzed in duplicate under randomized repeatability conditions. The Cochran test was used to detect analytical outliers with $95 \%$ confidence. Results were verified with the test for sufficient homogeneity [17]. The material is deemed to be sufficiently homogenous only if:

$s_{\text {sam }}^{2} \leq F_{1} \sigma_{\text {all }}^{2}+F_{2} s_{\text {an }}^{2}$,

where $s_{\text {sam }}^{2}$ is the between-unit variance, $s_{\text {an }}^{2}$ is the analytical variance, $\sigma_{\text {all }}^{2}$ is the allowable variance $\sigma_{\text {all }}^{2}=0.09 \sigma_{\mathrm{p}}^{2}$, that is equal to $30 \%$ of target standard deviation $\sigma_{p}$ ), and $F_{1}, F_{2}$ are statistical constants:

$F_{1}=\frac{\chi_{m-1,0.95}^{2}}{m-1}$

where $\chi_{\mathrm{m}-1,0.95}^{2}$ denotes value exceeded with probability 0.05 by a $\chi^{2}$ random variable with $m-1$ degrees of freedom.

$F_{2}=\frac{F_{m-1,0.95}-1}{2}$

where $F_{m-1,0.95}$ denotes value exceeded with probability 0.05 by a random variable with an $F$ distribution with $m-1$ degrees of freedom [16].

\section{Stability study}

The stability study was performed using isochronous approach described by Lamberty et al. [18]. The short-term stability under different storage conditions-in freezer $\left(-20{ }^{\circ} \mathrm{C}\right.$ with the limit $\left.\pm 2{ }^{\circ} \mathrm{C}\right)$ and in fridge $\left(6 \pm 4{ }^{\circ} \mathrm{C}\right)$ was tested over a period of 4 weeks. In addition, the longterm stability test was performed for samples stored at $-20{ }^{\circ} \mathrm{C}$ for 12 months. Reference samples were stored below $-70{ }^{\circ} \mathrm{C}$.

All samples were analyzed in duplicate under repeatability conditions in two runs (short- and long-term stability). The results were compared to the concentrations of DNC and NAR in samples stored in reference conditions.

\section{Evaluation of the material in European official control laboratories}

Randomly selected samples were put in polystyrene foam boxes with ice blocks, and sent by express courier to four European reference laboratories (EU-RL in Berlin and NRL of Ireland, Latvia and Portugal). All samples arrived at collaborating laboratories within 2 days from dispatch.
The laboratories employed their in-house routine test methods for analysis of the QCM sample. LC-MS/MS detection was employed in all of the collaborating laboratories and methods were validated according to $\mathrm{CD}$ 2002/657/EC [2]. The participants were asked to perform analysis in duplicate and provide individual results to NVRI, Pulawy, where they were evaluated statistically.

\section{Assigned values and uncertainty}

For the statistical evaluation, mean results from each laboratory (inter-laboratory comparison, $n=2$ for each of the four participants and homogeneity study, $n=20$ for NVRI) were used. Assigned values were expressed as a median of these results. Additionally, mean, standard deviation $(S D)$, coefficient of variation $(C V)$, and Horrat (ratio between obtained and target standard deviation) were calculated.

The combined uncertainty $\left(u_{\mathrm{QCM}}\right)$ includes contribution from homogeneity $\left(u_{\text {hom }}\right)$, long-term stability $\left(u_{\text {stab }}\right)$, and evaluation study $\left(u_{\text {eval }}\right)$ according to the equation [7]:

$u_{\mathrm{QCM}}=\sqrt{u_{\mathrm{hom}}^{2}+u_{\mathrm{stab}}^{2}+u_{\mathrm{eval}}^{2}}$

where

$u_{\mathrm{hom}}=\frac{C V_{\mathrm{hom}}}{\sqrt{n_{\mathrm{hom}}}}$

( $C V_{\text {hom }}$-coefficient of variation of homogeneity study, $n_{\text {hom }}$-number of replicates) [19]

$u_{\mathrm{stab}}=\frac{C V_{\mathrm{stab}}}{\sqrt{\sum\left(x_{i}-\bar{x}\right)^{2}}} \cdot x$

$\left(C V_{\text {stab }}\right.$ - coefficient of variation of all individual results in the stability study, $x_{i}$ - time point for each replicate (time from the beginning of the stability study), $\bar{x}$ - the average of all time points, $x$ - pre-defined shelf life -2 years) [20]

$u_{\mathrm{eval}}=\frac{C V_{\mathrm{eval}}}{\sqrt{n_{\mathrm{eval}}}}$

( $C V_{\text {eval }}$-coefficient of variation of means of laboratory results in evaluation study, $n_{\text {eval }}$-number of laboratories).

\section{Results and discussion}

Laboratories involved in the official residue control [1] often face problems with the availability of incurred samples that can be used for quality assurance. Most often, samples spiked with reference standard solutions are used for quality control. This solution is labor- and cost-effective but does not always provide the full information on the performance of the method. The CRMs would be an ideal 
Table 1 The results of homogeneity test of QCM for narasin and nicarbazin in eggs $s_{\text {an }}^{2}$-Analytical variance, $s_{\text {sam }}^{2}$ between-unit variance, $\sigma_{\text {all }}^{2}$ allowable variance, $s_{\text {crit }}-$ critical value for between-unit variance

\begin{tabular}{|c|c|c|c|c|}
\hline \multirow[t]{2}{*}{ Sample ID } & \multicolumn{2}{|l|}{ Narasin } & \multicolumn{2}{|l|}{ DNC } \\
\hline & Replicate $1(\mu \mathrm{g} / \mathrm{kg})$ & Replicate $2(\mu \mathrm{g} / \mathrm{kg})$ & Replicate $1(\mu \mathrm{g} / \mathrm{kg})$ & Replicate $2(\mu \mathrm{g} / \mathrm{kg})$ \\
\hline 1 & 7.50 & 6.30 & 12.4 & 15.1 \\
\hline 2 & 7.95 & 6.49 & 13.1 & 12.5 \\
\hline 3 & 6.88 & 7.51 & 13.4 & 13.5 \\
\hline 4 & 6.70 & 7.54 & 13.8 & 13.7 \\
\hline 5 & 6.93 & 6.45 & 13.0 & 14.6 \\
\hline 6 & 6.40 & 7.91 & 11.6 & 13.5 \\
\hline 7 & 7.57 & 9.01 & 15.7 & 14.3 \\
\hline 8 & 6.34 & 6.18 & 13.8 & 11.4 \\
\hline 9 & 6.13 & 7.14 & 12.1 & 13.0 \\
\hline 10 & 7.74 & 6.80 & 12.0 & 12.4 \\
\hline Mean $(\mu \mathrm{g} / \mathrm{kg})$ & 7.07 & & 13.3 & \\
\hline$S D(\mu \mathrm{g} / \mathrm{kg})$ & 0.753 & & 1.14 & \\
\hline$C V(\%)$ & 10.7 & & 8.6 & \\
\hline$s_{\text {an }}^{2}$ & 0.75 & & 1.06 & \\
\hline$s_{\mathrm{sam}}^{2}$ & 0.01 & & 0.17 & \\
\hline$\sigma_{\text {all }}^{2}$ & 0.22 & & 0.76 & \\
\hline \multirow[t]{2}{*}{$s_{\text {crit }}$} & 0.97 & & 2.57 & \\
\hline & $\mathrm{OK}$ & & OK & \\
\hline
\end{tabular}

solution, and their availability in the field of veterinary drug residues is, however, limited [8].

Therefore, in-house reference materials prepared from incurred samples and verified in terms of homogeneity and stability can play a significant role in the assurance of the reliability of the results of official residue control. Additionally, they can be used in the optimization of analytical steps that cannot be verified in another way (e.g., hydrolysis of phase II metabolites).

The reliability of quantitative results is very important especially for those compounds that are detected frequently in real samples from residue control plan. Within last few years, the majority of non-compliant results found in European Union related to antibacterials (group B1), coccidiostats (group B2b), and chemical elements (B3c) [12]. Most of the samples that contained coccidiostats were associated with poultry production (chicken tissues and eggs). A high percentage of non-compliant results were observed also in Poland [13]; therefore, the authors have decided to prepare the incurred QCM that would improve the quality assurance system.

The QCM contained two coccidiostats, namely nicarbazin and narasin. Nicarbazin (monitored in food as its DNC marker residues) is the most frequently detected coccidiostat in poultry meat and eggs analyzed in residue control, while narasin can be a challenging residue to quantify in food due to analytical difficulties from instability during sample preparation process and lack of proper internal standard. Additionally, the results of narasin determination could be an indication of the credibility of analytical process for other ionophore coccidiostats such as lasalocid, maduramicin, monensin, salinomycin, and semduramicin, which are relatively homogenous group of compounds.

The production and evaluation of QCM were carried out in accordance with "The international harmonized protocol for the proficiency testing of analytical chemistry laboratories" [16]. A lyophilized QCM was produced because of the known instability of narasin and the microbial degradation that occurs in materials having high water content $[21,22]$. The lyophilized material was stored in temperature below $-18{ }^{\circ} \mathrm{C}$, because it was considered that this would further extend its stability.

Biological material is usually heterogeneous to some degree so homogeneity study of prepared QCM should always be a first step in evaluation process [23]. The scheme of the homogeneity study was based on statistical analysis of duplicate results of 10 samples, according to the IUPAC Technical Report [16]. The obtained results and their statistical evaluation, presented in the Table 1, show that the between samples variation is negligible in comparison with the method repeatability. Therefore, the material was presumed to be sufficiently homogenous.

Following the homogeneity study, the stability of the material was evaluated. This experiment was performed using isochronous approach, which is based on the comparative analysis of stability samples with the samples stored in reference conditions (for which no degradation is expected) [18]. Such approach, apart from obvious advantage of time- and labor-effectiveness, generates the results in repeatability conditions, which improves their 
Fig. 1 The normalized content of nicarbazin (DNC) and narasin (NAR) during stability study at -20 and $+6{ }^{\circ} \mathrm{C}$ in comparison with samples kept at reference temperature $-70{ }^{\circ} \mathrm{C}$

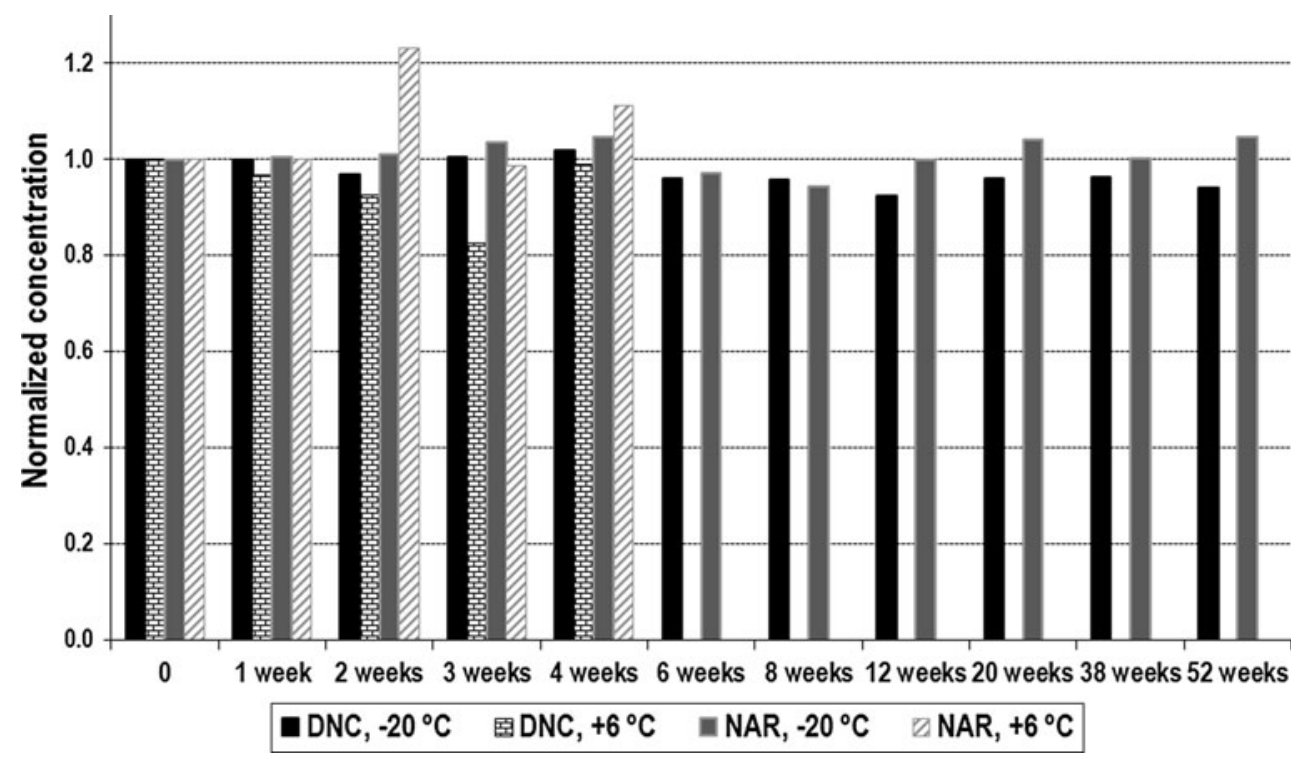

reliability. On the other hand, the time required to produce data is very long, and therefore, the stability test was performed in two runs-after 4 weeks and after 1 year from the production of QCM.

The reference storage conditions applied within this test $\left(-70{ }^{\circ} \mathrm{C}\right)$ were assumed to provide sufficient stability for lyophilized material. As the results of the determination of nicarbazin and narasin in reference samples did not differ significantly from those obtained in the homogeneity study, above assumption was confirmed.

For the purpose of stability testing, the samples were stored in temperatures expected to reflect the conditions applied afterward during the routine usage of the material. In short-term stability experiment, samples were stored both in -18 and $+6{ }^{\circ} \mathrm{C}$, whereas for the long-term study, only frozen storage $\left(-18{ }^{\circ} \mathrm{C}\right)$ was tested.

The results of the stability test are presented in the Fig. 1 and Table 2. No clear degradation pattern was observed for any of the analytes at either temperatures; therefore, the material was regarded as stable in applied storage conditions. The slope of the curve obtained from stability data is not significantly different from 0 , which further proves the stability of the material.

After initial verification of the produced material (homogeneity and short-term stability study), the material was sent to four European laboratories in order to obtain objective results in inter-laboratory comparison. All of laboratories taking part in this test are well recognized in the field of residue control (European Union Reference Laboratory in Berlin and three reference national laboratories) and used in-house developed and validated LC-MS/ MS methods. The results of the determination of nicarbazin and narasin in QCM obtained during inter-laboratory comparison are presented in the Table 3 .
Table 2 Long-term stability results and calculation of stability uncertainty $\left(u_{\mathrm{stab}}\right)$

\begin{tabular}{lll}
\hline Time (week) & NAR & DNC \\
\hline 1 & 1.0059 & 1.0006 \\
2 & 1.009965 & 0.967763 \\
3 & 1.036373 & 1.005158 \\
4 & 1.046233 & 1.018053 \\
6 & 0.970418 & 0.961589 \\
8 & 0.945166 & 0.957682 \\
12 & 0.999278 & 0.924766 \\
20 & 1.042357 & 0.960856 \\
38 & 1.002 & 0.964509 \\
52 & 1.047771 & 0.94 \\
$b(\% /$ year $)$ & 0.0282276 & -0.045107 \\
$|b| / s_{b}$ & 0.81 & 1.68 \\
Statistical significance $(95 \%$ conf. interval) & No & No \\
$u_{\text {stab }}(\%)$ & 6.76 & 6.07 \\
\hline$b$
\end{tabular}

$b$-Slope of the regression line of the stability measurements results, $s_{b}$-standard deviation of the slope of the regression line of the stability measurements results, $u_{\text {stab }}$-uncertainty of long-term stability (shelf life 2 years)

${ }^{\mathrm{a}} t_{0.05,10}=2.23$

Within the obtained data sets, no outliers were detected (Dixon's $Q$ test), and the reproducibility of the results was acceptable (Horrat 0.52 and 0.48 for NIC and NAR, respectively). The results of the independent analyses performed in four reference laboratories confirmed the results obtained in NVRI and enabled the assessment of assigned value, which is more realistic than the one determined in one laboratory. As it was never the authors' ambition to produce the CRM material having full 
Table 3 Evaluation of QCM in inter-laboratory comparison

\begin{tabular}{lcc}
\hline Laboratory & Result $(\mu \mathrm{g} / \mathrm{kg})$ & \\
\cline { 2 - 3 } & DNC & Narasin \\
\hline Laboratory 1 & 14.0 & 6.69 \\
Laboratory 2 & 17.4 & 8.22 \\
Laboratory 3 & 16.5 & 8.66 \\
Laboratory 4 & 14.4 & 7.91 \\
NRL Pulawy & 13.3 & 7.07 \\
Mean $(\mu \mathrm{g} / \mathrm{kg})$ & 15.1 & 7.71 \\
Median $(\mu \mathrm{g} / \mathrm{kg})$ & 14.4 & 7.91 \\
$S D_{\text {eval }}(\mu \mathrm{g} / \mathrm{kg})$ & 1.74 & 0.815 \\
$C V(\%)$ & 11.5 & 10.6 \\
Target $S D(\mu \mathrm{g} / \mathrm{kg})$ & 3.32 & 1.696 \\
Target $C V(\%)$ & 22.0 & 22.0 \\
Horrat & 0.52 & 0.48 \\
\hline
\end{tabular}

Table 4 Assigned values, relative standard uncertainties of individual contributions, combined standard uncertainties, and expanded uncertainties of QCM

\begin{tabular}{lcc}
\hline & DNC & Narasin \\
\hline$u_{\text {hom }}(\%)$ & 3.79 & 5.00 \\
$u_{\text {stab }}(\%)$ & 6.07 & 6.76 \\
$u_{\text {eval }}(\%)$ & 5.14 & 4.72 \\
$u_{\mathrm{QCM}}(\%)$ & 8.81 & 9.64 \\
$U_{\mathrm{QCM}}(k=2)(\%)$ & 17.6 & 19.3 \\
Assigned value $(\mu \mathrm{g} / \mathrm{kg})$ & 14.4 & 7.91 \\
$U_{\mathrm{QCM}}(\mu \mathrm{g} / \mathrm{kg})$ & 2.53 & 1.52 \\
\hline
\end{tabular}

traceability characteristics, the inter-laboratory comparison with five participants of recognized credibility seems to be a good compromise between labor expenditure and reliability of obtained results.

As the last step of QCM evaluation, the uncertainty of the material was assessed (Table 4). The calculation was performed analogously to the protocols described before for certified materials [7] and included the uncertainty of all the stages of evaluation of QCM, described above.

The quality control material containing incurred residues of narasin and nicarbazin in lyophilized eggs has been prepared and characterized. Such material can serve as a cost- and labor-effective alternative to CRM in method development, validation, and quality control.

Acknowledgments The authors would like to gratefully acknowledge laboratories participating in inter-laboratory comparison: Federal Office of Consumer Protection and Food Safety, BVL (Berlin, Germany), Food Safety Department, Teagasc Food Research Centre (Ashtown, Dublin 15, Ireland), National Diagnostic Center (Riga, Latvia), and Laboratorio Nacional Investigacão Veterinaria (Lisbon, Portugal).
Open Access This article is distributed under the terms of the Creative Commons Attribution License which permits any use, distribution, and reproduction in any medium, provided the original author(s) and the source are credited.

\section{References}

1. Council Directive 96/23/EC of 29 April 1996 on measures to monitor certain substances and residues thereof in live animals and animal products and repealing Directives 85/358/EEC and 86/469/EEC and Decisions 89/187/EEC and 91/664/EEC (1996) Off J Eur Commun L 125: 10-32

2. Commission Decision 2002/675/EC of 12 August 2002 implementing Council Directive Directive 96/23/EC concerning the performance of analytical methods and the interpretation of results (2002) Off J Eur Commun L 221: 8-36

3. Anklam E, Holst C (2005) Challenges and needs in food measurements. Anal Bioanal Chem 381:102-105

4. O'Keeffe M, Nugent A, Cadogan A, Hopkins JP, Daeseleire E, van Peteghem C (1997) Development of bovine muscle, liver and urine reference materials for zeranol-preparation, homogeneity and stability. Fresenius J Anal Chem 357:1029-1034

5. Pfaffl MW, Ginkel LA, McEvoy JDG, Maghuin-Rogister G, Meyer HHD (2001) Development of clenbuterol reference materials: lyophilized bovine eye samples free of clenbuterol (CRM 673) and containing clenbuterol (CRM 674) Part 2: certification. Fresenius J Anal Chem 371:1086-1097

6. IRMM reference material catalogue, http://www.irmm.jrc.be/ html/reference_materials_catalogue/catalogue/index.htm

7. Zeleny R, Schimmel H, Ulberth F, Emons H (2009) Development of a certified reference material for the content of nitroimidazole parent drugs and hydroxy metabolites in pork meat. Anal Chim Acta 634:237-242

8. Zeleny R, Ulberth F, Gowik P, Polzer J, van Ginkel LA, Emons H (2006) Developing new reference materials for effective veterinary drug-residue testing in food-producing animals. Trends Anal Chem 25:927-936

9. Bohm DA, Stachel CS, Hackenberg R, Gowik P (2011) Preparation and characterisation of in-house reference material of tylosin in honey and results of a proficiency test. Anal Chim Acta 700:58-62

10. Jiménez V, Companyó R, Guiteras J (2012) Analysis of quinolone antibiotics in eggs: preparation and characterization of a raw material for method validation and quality control. Food Control 134:1682-1690

11. Jedziniak P, Szprengier-Juszkiewicz T, Olejnik M (2009) In-house reference materials: 5-hydroxy-flunixin and meloxicam in cow milk-preparation and evaluation. Anal Chim Acta 637:346-350

12. EFSA (2011) Report for 2010 on the results from the monitoring of veterinary medicinal product residues and other substances in live animals and animal products. Supporting Publications 2012:212

13. Olejnik M, Szprengier-Juszkiewicz T, Jedziniak P, Śledzińska E, Szymanek-Bany I, Korycińska B, Pietruk K, Żmudzki J (2011) Residue control of coccidiostats in food of animal origin in Poland within years 2007-2010. Food Addit Contam Part B 4:259-267

14. Olejnik M, Szprengier-Juszkiewicz T, Jedziniak P (2011) Depletion study of nicarbazin and narasin in tissues and eggs of hens housed in deep litter. Bull Vet Inst Pulawy 55:761-766

15. Olejnik M, Szprengier-Juszkiewicz T, Jedziniak P (2010) Confirmatory method for the determination of coccidiostats in eggs. Bull Vet Inst Pulawy 54:327-333 
16. Thompson M, Ellison SRS, Wood R (2006) The international harmonized protocol for the proficiency testing of analytical chemistry laboratories (IUPAC Technical Report). Pure Appl Chem 78:145-196

17. Thompson M (2004) AMC recommendation, http://www.fapas. com/pdfpub/Paper_2_Amc\%20recommendation.pdf

18. Lamberty A, Schimmel H, Pauwels J (1998) The study of the stability of reference materials by isochronous measurements. Fresenius J Anal Chem 360:359-361

19. ISO Guide 35 (2006) Reference materials. General and statistical principles for certification
20. Linsinger T, Pauwels J, Lamberty A, Schimmel H, van der Veen AMH, Siekmann L (2001) Estimating the uncertainty of stability for matrix CRMs. Fresenius J Anal Chem 370:183-188

21. Amigo JM, Arana G, Etxebarria N, Fernandez LA (2004) Emerging needs for sustained production of laboratory reference materials. Trends Anal Chem 23:80-85

22. Rückhold S, Grobecker KH, Isengard H (2001) Water as a source of errors in reference materials. Fresenius $\mathrm{J}$ Anal Chem 370:189-193

23. Pauwels J, Lamberty A, Schimmel H (1998) Homogeneity testing of reference materials. Accred Qual Assur 3:51-55 